\title{
Creating a Scale for assessing Socially Sustainable Tourism
}

\begin{abstract}
:
As destinations absorb even increasing number of visitors, destination managers become progressively more concerned about the longer term viability of tourism from a resident's perspective. However, few studies have examined the application of real time social sustainability within tourism, particularly how to measure impacts on social sustainability. This study outlines the development of a valid and reliable scale - the Scale of Social Sustainability (SSS) - for tourism that provides an assessment of social sustainability in destination settings. A 10-step procedure was developed drawing upon the related literature. A telephone poll-based survey generated 1,839 valid responses from Hong Kong residents. Hong Kong’s growing popularity as a destination provides a rich array of host-guest conflict situations. Dimensionality was identified using exploratory and confirmatory factor analyses. Construct validity, reliability, and stability were assessed, and found good, showing that the scale could be used by other destinations worldwide. The theoretical and managerial implications of the scale are discussed, including options for annual surveys giving policy makers alerts before situations worsen. Detailed host resident viewpoints, and the large scale of the survey can help local residents be informed about tourism development and better involved in the policy formation process.
\end{abstract}

Keywords: Scale of Social Sustainability (SSS), host-guest conflict, social tolerance, social acceptance, Hong Kong 


\section{Introduction}

The concept of social sustainability has attracted increasing attention from tourism researchers worldwide because of rapidly increasing tourist arrivals and growing awareness of the influence on resident attitudes of such intrusions. Tourism development concerns many destinations because of various negative effects on local residents and communities. These include loss of traditional culture and customs, increased crime rates, and over-crowding. To cope with potential disequilibrium in destination communities, many researchers have identified the effects of tourism and have proposed a range of solutions to ameliorate the situation.

In explaining the concept of sustainable tourism, scholars have developed a range of assessment tools (Boley \& McGehee, 2014; Choi \& Sirakaya, 2005; Gursoy \& Rutherford, 2004; Latkova \& Vogt, 2012; Perdue, Long \& Allen, 1990; Sirakaya-Turk, Ekinci, \& Kaya, 2008; Teye, Sönmez \& Sirakaya, 2002; Tosun, 2002; Weaver \& Lawton, 2001; Williams \& Lawson, 2001; Yu, Chancellor, \& Cole, 2011). These studies have demonstrated that the social effects of tourism have attracted increasing attention because of the negative community responses to increasing tourist numbers. The attainment of sustainable tourism is compromised when there is an overemphasis on economic aspirations and ignorance about the retention of social and cultural identities amongst residents. Policy makers and tourism organizations have challenged by the need to balance the social and economic effects of tourism. Various studies have identified the effects of tourism, but relatively few have emphasized the social aspects. Moreover, there has been little effort to develop measurement tools that can assess social sustainability from the host community perspective. 
To facilitate the social sustainability of tourism in host communities, this study develops and validates a scale - the Scale of Social Sustainability (SSS) - for tourism. The approach involved the conduct of an extensive literature review, in-depth interviews, and review by a panel of experts. The structure of the measurement scale was explored and confirmed using exploratory factor analysis (EFA) and confirmatory factor analysis (CFA). The construct validity and reliability were examined using multi-tests, including content validity, convergent validity, discriminant validity, nomological validity, Cronbach's alpha, and composite reliability. The stability of the construct structure was subsequently assessed by splitting the data into groupings according to higher and lower resident attraction densities. This approach has the benefit of providing more nuanced insights into different destination settings. The study results may be of benefit to both academics and practitioners, and eventually to residents and tourists. It provides theoretical contributions to the sustainable tourism literature by building and validating a measurement tool that assesses social sustainability from the viewpoint of local residents. From a practitioner perspective, the proposed measurement instrument provides an opportunity to evaluate social sustainability from the host community perspective and to proceed with appropriate remedial actions. This focus of the present investigation is Hong Kong because of the growing host-guest conflicts that are attributable to the increasing visitation from mainland China.

\section{Literature Review}

There is a substantial literature on sustainable tourism. The World Commission on Environment and Development (WCED, 1987) defines sustainable development as a process to 
meet the needs of the present without compromising the ability of future generations to meet their own needs. The United Nations World Tourism Organization (UNWTO, 1995) defined sustainable development as a tourism process that meets the needs of present tourists and host regions, and protects and increases their opportunities for future prosperity.

Sustainable development consists of three core dimensions, namely: economic, social, and environmental sustainability. According to the definitions that are provided by UNEP and UNWTO (2005), social sustainability requires the upholding of human rights, the provision of equal opportunities, the equal distribution of benefits, and the alleviation of poverty. The concept also focuses on improving the livelihood of local communities, maintaining and strengthening their life support system, preserving traditional cultures, and preventing exploitation. Butler (1999) and McIntyre (1993) suggested that sustainable tourism should cover all dimensions of sustainability, including planning, full community participation, and the protection of community resources.

\section{Social Sustainability and Tourism}

In seeking to benefit local residents, sustainable tourism should also minimize any detrimental effects on the culture and environment of host communities (Yu et al., 2011). Achieving social sustainability involves making significant efforts that will contribute to local communities by balancing and monitoring the social effects of tourism, notably on hosts' quality of life, on the distribution of benefits, on life supporting systems, and on cultural preservation (UNEP \& UNWTO, 2005). Studies of sustainable tourism have often emphasized the tendency of tourism development to produce diverse results. Several studies have explored the effects of 
tourism on host residents and communities, and a summary of 140 of these can be found in Nunkoo, Smith, and Ramkissoon (2013). The major negative effects of tourism include traffic congestion, individual and organized crime, drug addiction, and alcoholism. It has frequently been noted that the positive effects of tourism relate primarily to economic aspects, such as employment opportunities, increased incomes, improved living standards, and a growth of the tax base. Other positive benefits of tourism include enhanced quality of life, the provision of hospitality to strangers, and enhanced confidence amongst residents (King et al., 1993; Milman \& Pizam, 1988). It has been found that resident attitudes to tourism are significantly influenced by personal and locational characteristics, by contact with tourists, length of residence, age, and language (Brougham \& Butler, 1981). Studies on the reactions of residents to tourism have applied a range of theoretical perspectives, including social exchange theory, the perceived costs and benefits of a certain relationship, and their implications for the achievement of satisfying relationships (Ap, 1992; Nunkoo \& Ramkissoon, 2012; Ward \& Berno, 2011). Several empirical studies have explored social effects by applying Butler's (1980) theory - the Tourism Area Life Cycle (TALC). The findings have demonstrated that social effects are present at each stage of the cycle (Yang, Ryan \& Zhang, 2014) and have often been exacerbated during the destination consolidation and stagnation stages, leading to the exhaustion of carrying capacity (Aledo \& Mazon, 2004). Negative social effects may lead to destination decline (Diedrich \& Garci'aBuades, 2009). High visitation and a proliferation of accommodation facilities can arouse discontent and conflict amongst residents. During the destination consolidation or stagnation stages, resources may exceed their capacities, leading to various environmental, social, and economic problems. 


\section{The Measurement of Social Sustainability}

As the tourism industry has continued to expand internationally, growing concerns have been expressed about the negative effects of visitation, prompting researchers to develop tools that assess tourism sustainability from different perspectives. To obtain an overall understanding of current social sustainability research, a comprehensive literature review was conducted of articles in the most directly applicable top tier tourism journal, Journal of Sustainable Tourism. The review was conducted in three stages. Firstly, the researchers determined that "social sustainable”, "social sustainability”, “social impact” and "resident perceptions” would be the relevant search criteria. The final selection consisted of those which included any of the keywords within the titles, keywords or abstracts. At the initial stage, a total of 38 results was obtained. To further refine the search, a second stage involved undertaking a review of the content of the various articles to ensure that social sustainability was either the main research topic or formed part of the research content. At the end of this stage, 27 articles were identified and then used to form the review pool. Details are included in Appendix 1, which is a supplementary file available on the web based version of this paper. The researchers concluded that the qualitative and quantitative methods that have been used in the study of social sustainability share similar weightings. Relatively less research has made use of mixed methods. Questionnaire based surveys were predominant in the various quantitative studies, whereas interviews and participant observations have been commonly adopted in the qualitative studies. Social Exchange Theory was the most applied theory, followed by the Tourism Area Life Cycle. The most researched areas were tourism impacts and resident attitudes. It was a surprising finding about measurement scales that only one out of 27 social sustainability related articles explores social sustainability measurement in the tourism context. This particular study was undertaken 
from a backpacker perspective. The review revealed an urgent need to identify an accurate measurement of social sustainable tourism from the host perspective.

A comprehensive review was undertaken of the various available measurements of social sustainability, focusing on articles that relate to tourism sustainability scales. Tourism scholars have proposed various sustainability related dimensions that apply in different settings. Perdue et al. (1990) pioneered a model that included different constructs, such as resident perceptions of tourism impacts, personal benefit, support for additional tourism development and restrictions on tourism development. The model was extended by Latkova and Vogt (2012), who applied the theories of Social Exchange Theory and Tourism Area Life Cycle. Perceived impacts on prices, crime, quality of life, government control, and traffic issues were discussed as they apply in the case of higher or lower tourist volumes and in areas characterized by higher or lower incomes (Allen et al., 1993). The Tourism Impact Attitude Scale (TIAS) was originally designed to standardize the measurement of resident attitudes towards tourism development (Lankford \& Howard, 1994). Tosun (2002) undertook comparative studies of resident perceptions towards the effects of tourism in Turkey, Fiji, and the United States. In this study three tourism effect dimensions were proposed, namely: legal, social, and economic. Various studies have addressed the issue of perceptual differences across different nations. Choi and Sirakaya (2005) proposed a well-developed measurement of sustainability and developed a seven-dimension measurement instrument which was tested in various research settings (Sirakaya-Turk et al., 2008; Yu et al., 2011). These dimensions included environmental sustainability, social costs, economic benefits, community participation, long-term planning, visitor satisfaction, and the community-centered economy. Recently, more attention has been given to the emotional solidarity and empowerment of residents. These were utilized to measure resident attitudes towards tourism development 
(Boley \& McGehee, 2014; Boley, McGehee, Perdue \& Long, 2014; Boley, Maruyama \& Woosnam, 2015; Woosnam, 2012).

Several conclusions may be drawn from this substantial body of work. Firstly, although some measurement instruments have been developed to quantify the extent to which tourism is sustainable, few studies have focused on the social aspects of sustainable tourism. Social sustainability has been treated as a single component under the overall concept of sustainable tourism. On this basis, the investigation of social sustainability in tourism remains inconsistent and in need of further refinement. Moreover, the inadequacies are evident of scales that simply view the social element as a single dimension of overall sustainable measurement (Allen et al., 1993; Boley \& McGehee, 2014; Choi \& Sirakaya, 2005). They are unable to deliver comprehensive information according to guidelines that have been developed by UNEP and UNWTO (2005). Secondly, the respective concepts of social sustainability and of social effects in tourism have remained mutually independent. Various studies on the social effects have provided minimal information to offer genuine assistance to individuals who are attempting to cope with long-term sustainable development. The various studies about social sustainability have made minimal effort to transform the dimensions of social effect into an evaluation tool that can support the processes of social sustainability. It is, therefore, timely to undertake an integrated study that introduces social effects into the assessment of social sustainability as a potential contribution to both the theoretical and practitioner literature. Thirdly, as noted in the literature, social sustainability may vary in different destination settings. Unfortunately, few researchers have used rigorous statistical techniques to test the structural stability of measurements of tourism sustainability in different contexts. This may have hindered the development of social sustainability from both an academic and a practitioner perspective. To address these research 
gaps, this study uses Hong Kong as the host location to develop a valid and reliable measurement tool to assess the social sustainability of tourism development.

\section{Research Context: Mainland Chinese Traveling to Hong Kong}

Mainland Chinese tourists are crucial to the success of Hong Kong's tourism industry. After the negative international publicity that flowed from the SARS crisis in 2003, the mainland Chinese government attempted to help recovery of the Hong Kong economy by stimulating the tourism sector through the introduction of the Individual Visit Scheme (IVS). The IVS allowed mainland Chinese tourists from approved cities, such as Shanghai, Beijing, and Guangzhou, to make individual visits to Hong Kong. The scheme was subsequently expanded to 49 mainland cities. A further expansion of the IVS occurred in 2009 in response to the slowdown associated with the Global Financial Crises. This change created problems when an additional four million Shenzhen residents were endorsed for one-year multiple-entry visits into Hong Kong. Mainland Chinese tourists increased from 8.47 million in 2003 to 47.2 million in 2014, accounting for 77.7\% of all tourist arrivals in 2014 (Hong Kong Tourism Board, 2015). The SAR has a resident population of only 7 million, occupying a landmass of only 1,104 square kilometres. Such a substantial volume of tourism has inevitably affected both residents and infrastructure. To date, however, there has been no available formula to evaluate the presence of such a volume of visitation and its impacts.

Despite the substantial economic benefits that mainland Chinese tourists bring to Hong Kong, visitor inflows have been associated with problems that include an increase in the prices charged for consumer goods and property (Chow, 2012) and excessive use of public resources 
(Ye, Zhang, \& Yuen, 2012). Rapid tourism growth has also driven mainland Chinese tourists to make incursions into the less visited areas, further affecting community wellbeing. Many mainland Chinese tourists have shown a preference for traveling both widely and individually rather than being confined to group-based travel. Visiting "backstage” settings may be associated with additional social problems, such as the emergence of cultural conflicts between tourists and locals and disturbing the lifestyles of residents (Liu \& McKercher, 2014; Ye et al., 2012). The negative effects now faced by local Hong Kong residents have prompted the authorities to determine how to balance the social effects and economic benefits that are being brought by Chinese travellers. In view of the actual and potential tensions between residents and tourists, the social effects of tourism on Hong Kong's future tourism development need urgent review. This is not least because the long-term sustainability of this market depends on the acceptance by local communities of the tourism-related improvements in their wellbeing and on a harmonious relationship between hosts and guests.

\section{Methodology}

Measurement instruments play an essential role in research design and may influence the results. Validity and reliability are two core development criteria. Several researchers have studied the procedure of developing an appropriate measurement instrument (Boley \& McGehee, 2014; Chen \& Hsu, 2001; Churchill, 1979; Echtner \& Ritchie, 1993; Hung \& Petrick, 2010; Yu et al., 2011). Churchill (1979) pioneered measurement development and provided clear, comprehensive steps for the development of a reliable and valid measurement instrument. These steps were used as a guideline for the present paper. The Churchill (1979) framework attempted 
to unify and assemble the scattered pieces of information on how measurement could be improved and on how the quality of derived measurements could be accurately assessed. Several studies have applied such procedures in different research settings. Echtner and Ritchie (1993) used the procedure's first four steps to develop an appropriate and rigorous technique for assessing destination image. Hung and Petrick (2010) used all eight steps and adopted components from the Churchill framework to develop a comprehensive list of cruise constraints.

Churchill (1979) proposed that, researchers should demonstrate flexibility when applying his procedures. In the present case, a triangulated analysis was performed to collect information from diverse sources with a view to developing a comprehensive measurement of social sustainability. Echtner and Ritchie (1993) argued that multiple techniques are needed to produce a comprehensive set of measurement items. The present study involved a literature review, indepth interviews, and a telephone-based poll for triangulation purposes. A 10-step approach was adopted for the purposes of developing the social sustainability measurement instrument (see Table 1).

\section{Insert Table 1 Here}

The literature review covered the domain of social sustainability. Initially, a pool of items was generated by reviewing and summarizing the existing social sustainability research. In-depth interviews were conducted with 8 major stakeholders, including the Travel Industry Council, Hong Kong Tourism Board, Quality Tourism Services Association, Hong Kong Association of Travel Agency, Hong Kong Hotel Association, Ocean Park, Disneyland, and the China National Tourism Administration. It was anticipated that these would provide additional insights about the relationship between mainland China tourists and Hong Kong. Each interview lasted for about an 
hour. Stakeholder views were collected from both the tourism-related sectors and from the broader community as a basis for building consensus. Existing studies and interview transcripts were also reviewed to generate 29 items covering local satisfaction, local perception, local complaint, local control, visitor behaviour, community wellbeing, social equity, and cultural richness (Fredline \& Faulkner, 2000; Lawson, 2001; Su \& Lin, 2004; To, 2006; Tosun, 2002; UNEP \& UNWTO, 2005; UNWTO, 2004). The applicability of these items was reviewed by a panel that included five Hong Kong Polytechnic University faculty members who were knowledgeable about sustainable tourism. The items were revised and included in a draft questionnaire that drew upon the comments that were received from the panel.

A pilot study was conducted to identify potential problems in the questionnaire design. Eighty written questionnaires were collected from locally based Hong Kong Polytechnic University students. Necessary amendments were made to improve the questionnaire design. Ultimately, a list of 24 items was compiled for the purposes of conducting the study. (see Appendix 2, which is a supplementary file available on the web based version of this paper.)

\section{Data Collection}

A sample size of 2,000 was targeted for this study, and the interviews were conducted by telephone, an increasingly popular research method in social science studies. Scholars have documented various advantages that are associated with telephone interviews, especially where random sampling dialling is available. These include an equal chance of selection, reduced interviewer effects, a low tendency to provide socially desirable responses, and low cost in terms of time, labour, effort and money (Carr \& Worth, 2001; Robson, 1993). It facilitates interviewers 
with quality control and security issues (Marcus \& Crane, 1986). There are also some disadvantages, such as the difficulty of building rapport, lack of visual cues, limitations on interview length and complexity (Carr \& Worth, 2001; Lavrakas, 1987; Robson, 1993). It may also disregard groups who are unable to communicate via phone; some smartphone users may also decline calls from unlisted numbers. There are, however, techniques to help overcome these limitations.

Quota sampling was performed in selecting prospective survey respondents based on the current geographical distribution of the Hong Kong population. Hong Kong Island, Kowloon, and the New Territories have populations of 1,277,200 (17.9\%), 2,146,800 (30.0\%), and 3,729,600 (52.1\%), respectively, as reported in the 2012 Census (Hong Kong Census \& Statistics Department, 2013). Totals of 358, 600, and 1,042 residents from each of Hong Kong Island, Kowloon, and the New Territories were selected for the telephone interviews.

The survey was limited to permanent Hong Kong residents aged 18 years or above. It was conducted from July 15, 2014 to August 14, 2014 by the computer-assisted survey team (CAST) from the Centre for Social Policy Studies (CSPS) of The Hong Kong Polytechnic University. The CAST used a structured questionnaire for respondents in colloquial Chinese. The computer assisted telephone interviews (CATI) system was used to collect the required information for purposes of analysis. The telephone numbers were identified via simple random sampling, and the respondents were selected using the last-birthday method. Before considering a respondent as unreachable for interviewing, the interviewers were required to make contact on at least three occasions. 
To test the applicability of the questionnaire in CATI, 15 pilot telephone interviews were conducted, and any necessary modifications were made. A total of 1,839 cases were then successfully collected and processed for purposes of data analysis. A telephone survey's response rate is not usually reported as the calculations are problematic given the great number of dispositions possible (Gripp, Luloff \& Yonkers, 1994) and its influence on the survey result is limited (Keeter et al., 2000; Fowler, 1984). Instead, cooperation rate and contact rate are preferred to represent the efficiency of a telephone survey (Gripp et al., 1994). According to Groves's equation (1989), the overall cooperation rate is $42.41 \%$ and the contact rate is $85.75 \%$. Further details on the telephone survey are shown in Table 2.

\section{Insert Table 2 Here}

\section{Data Analysis}

Upon their collection for processing purposes, all responses were categorized, scaled, and entered into the Statistical Package for the Social Sciences program. Data screening was conducted to detect outliers and any serious violations of assumptions. Descriptive analysis (e.g., frequency and means) was performed to profile the respondent characteristics and to compose the descriptive information of all attributes. EFA was performed to reduce the number of items and to explore the dimensionality of each construct. Cronbach's alpha was generated to assess the internal reliability of the factors. CFA was subsequently performed via the Analysis of Moment Structures to undertake further purification of the structure and dimensionality of the factors. Composite reliability was performed to examine the internal reliability of each factor. The validity of these factors was tested using convergent validity, discriminant validity, nomological validity and overall fit indices. The structural stability of each factor was tested by splitting the 
sample into two subsets. The following section provides a more detailed discussion of the data analysis process.

\section{Findings}

\section{Respondent Demographic Profiles}

Following quota sampling, the respondents were randomly selected from all the 18 districts in Hong Kong. Table 3 shows the demographic profile of the respondents. A total of 1,839 valid responses were collected. Female respondents (55.5\%) outnumbered their male counterparts (44.5\%), and both groups were widely distributed in terms of age. Approximately $44.5 \%$ and $31.9 \%$ of the respondents were holding secondary/matriculation and bachelor or higher-level degrees, respectively. Most respondents were working (56.6\%), of whom nearly onethird occupied in managerial or professional roles and $13.3 \%$ were working in jobs that were either directly or indirectly related to the tourism industry. This means that about $87 \%$ of the respondents were from non-tourist related sectors. This helped to provide independent views from a selection of all Hong Kong residents without being affected by their involvement in or knowledge about the tourism industry. Given the sensitivity of the topic, only 51.1\% of respondents disclosed their income during the phone conversation. Roughly $28 \%$ of the respondents earned a monthly income ranging from $10,000 \mathrm{HK} \$$ to $30,000 \mathrm{HK}$. Considering the generalizability of the survey, the demographic profile of respondents in the current study was comparable to that reported by the Hong Kong Census and Statistics Department (2012), as indicated in Table 3. The comparison revealed that the two samples are similar for gender, marital status, age, educational attainment, working status, industry occupation as well as 
monthly personal income. Because of limited information about tourism related jobs, this particular category cannot be aligned with the census report.

\section{Insert Table 3 Here}

\section{Dimensionality and Validation-Exploratory Factor Analysis}

EFA was performed on the 24 items to reduce their number and to explore the dimensionality of the social sustainability measurement instrument. This helped to identify the latent constructs represented in the original variables via CFA. Principal axis factoring was selected as the appropriate extraction method. This method considers only the common or shared variances and assumes that both the unique and error variances are not of interest in defining the structure of variables (Hair, Black, Babin, \& Anderson, 2010). This method is also perceived to be more theoretically based than other extraction methods, such as principal components analysis. Direct oblimin rotation was used to handle the correlated factors.

The 24 items were entered into the system during the initial stage. Items Q5, Q14 and Q22 were removed from the questionnaire because of their cross-loadings on more than one factor, generating factor loading scores equivalent to or exceed 0.30. Items Q1, Q6, Q9, Q10 and Q23 were also excluded from further analysis because their factor loadings were lower than 0.40. EFA unveiled three underlying dimensions. Table 4 shows the factor loadings of each remaining item and the Cronbach’s alpha for each construct. All of the 16 items held satisfactory factor loadings equal to or above 0.434 on their corresponding factors. The appropriateness of factor analysis was subsequently tested using the Kaiser-Meyer-Olkin (KMO) measure of sampling adequacy and Bartlett's test of sphericity. An acceptable KMO value of 0.907 and a significant 
Bartlett's test of sphericity $(\mathrm{p}<0.000)$ were obtained, which verified the existence of a sufficient number of correlations among the variables. The Cronbach's alpha for each factor ranged from 0.904 to 0.687 , which indicated the favourable internal reliability for the three factors. Consequently, 16 of the 24 items were retained and divided into three factors, namely, HostGuest Conflict (10 items), Social Tolerance (3 items), and Social Acceptance (3 items).

\section{Insert Table 4 Here}

\section{Assessing Factor Structure Stability}

The stability of the factor model is crucial to the generalizability of the research findings. Hair et al. (2010) suggested that factor stability depends primarily on the sample size and on the number of cases per variable. On this basis researchers are encouraged to obtain a larger sample size and to increase the cases-to-variables ratio. Splitting the sample into two subsets and estimating the factor models for each subset may also facilitate the examination of factor model stability (Hair et al., 2010). Comparing the results from the overall sample and the sub-samples may provide additional evidence on the robustness of the solution across the sample. The overall sample was further divided into two subgroups based on the resident-attraction density. Hong Kong has 18 districts across its three regions, namely, Hong Kong Island, Kowloon, and the New Territories. The resident population and number of tourists vary across these districts. The researchers sought to compare the social sustainability measurement in both the high- and lowdensity areas. Given the lack of statistical information on tourists in each district, the number of tourist attractions was used to represent such information. The resident-attraction density was calculated using the following equation, which considered the population and attraction densities in a particular district: 


$$
\text { resident }- \text { attraction density }=\sqrt{\left(\frac{\text { district population }}{\text { district area }}\right)\left(\frac{\text { no. of attractions in district }}{\text { district area }}\right)}
$$

The resident-attraction density for the 18 districts ranged from 0.013 to 0.518 . The highand low-density areas were determined based on the density distribution for the 18 districts, using 0.1 as the cut-off line. Eight districts (i.e., Central and West, Wan Chai, East, Yau Tsim Mong, Sham Shui Po, Kowloon City, Wong Tai Sin, and Kwun Tong) were identified as high residentattraction density districts, whereas 10 districts (i.e., South, Tsuen Wan, Kwai Tsing, Sai Kung, Sha Tin, Tai Po, North, Tuen Mun, Yuen Long, and Island) were categorized as low residentattraction density districts. The districts in Hong Kong Island (except South) and Kowloon were classified as high resident-attraction density regions, whereas the districts in the New Territories were classified as low resident-attraction densities. The factor model that was derived from the overall sample was re-examined in both subgroups. As indicated in Table 4, 832 and 988 respondents were selected from the high- and low-density groups, respectively. The sum of these two subgroup samples was not equivalent to 1,839 because 19 respondents failed to provide their addresses, and were thus excluded in the calculation of high- and low-density groups. The EFA results for both groups were consistent with the factor model that was derived from the overall sample. The KMO values for the high- and low-density regions were 0.896 and 0.904 , respectively, which were both higher than the required value of 0.6 (Chen \& Hsu, 2001). Bartlett's test of sphericity was significant in the case of both groups. Most of the factor loadings were greater than the 0.4 requirement, except Q24 in the high-density group (0.377). All of the factors had Cronbach's alpha values that exceeded 0.7. Although the Social Acceptance factor obtained a slightly lower Cronbach’s alpha (0.683-0.692), this value was still acceptable because of the exploratory nature of this study (Hair et al., 2010). On this basis the factor structure 
stability was supported. The dimensionality of the social sustainability measurement instrument was generally consistent between the high and low resident-attraction density groups.

\section{Construct Validity and Reliability—Confirmatory Factor Analysis}

CFA was performed with a view to further validating the 16 -item measurement scale. The EFA results were used as a basis for creating a hypothetical model with three constructs. The structural model was assessed in terms of its validity and reliability. The construct validity was examined by convergent, discriminant and nomological validity. Missing data were eliminated via listwise deletion before conducting CFA to avoid drawing any biased conclusions from an

empirical study. Two cases were deleted during the assessment of normality and outliers because of their high Mahalanobis d-squared values. A total of 1,406 cases were retained for the next round of analysis.

The extent of the correlation between the intended measure and the other measures in the construct was evaluated using convergent validity (Clark-Carter, 1997). Convergent validity represents the internal consistency of the variables within one construct. The standardized itemto-factor loading magnitude should be at least 0.5 , and the factor loadings should reach the level of statistical significance (Hair et al., 2010). The primary CFA result suggested that most of the factor loadings exceeded 0.5 and all factor loadings were statistically significant $(\mathrm{p}<0.001)$. Two items in the Host-Guest Conflict dimension (Q8 and Q15) were eliminated because their factor loadings were lower than 0.5. Average variance extracted (AVE) was also calculated for each construct to estimate the convergent validity, and the results were $0.503,0.506$ and 0.433 respectively. Though the ideal AVE for a well-developed construct should be equal to or above 
0.5 (Hair et al., 2010), Netemeyer, Bearden, and Sharma (2003) suggested that a newly integrative scale should have an AVE value of .45 or higher. Due to the exploratory nature of the current study, most of the items were newly developed from preceding literature, interviews and panel discussion. Given this, the Social Acceptance, as per Netemeyer et al. (2003), is seen as being close to the threshold. The convergent validity was established when all facts were considered (Song, Xing \& Chathoth, 2015; Ye et al., 2012). Each factor consisted of three or more items that met the baseline of favourable practices (Hair et al., 2010). All of the retained items and their corresponding factor loadings are shown in Table 5.

\section{Insert Table 5 Here}

The differences between constructs are examined using discriminant validity (Byrne, 2010). Discriminant validity monitors the external dissimilarity among factors (Hung \& Petrick, 2010). The test does not provide strong evidence of discriminant validity if the squared correlation between any two constructs exceeds the corresponding AVE. In this study, each of the squared correlations between any two constructs was smaller than the corresponding AVE (see Table 6, which is a supplementary file available on the web based version of this paper), confirming the discriminant validity of the measurement scale. Finally, the nomological validity was conducted to examine the correlations among the constructs in a measurement model which should be theoretically related (Hair et al., 2010). This technique was broadly applied in measurement developing studies and was stated to be an efficient approach to testing construct consistency within a measurement scale (Boley \& McGehee, 2014; Boley et al., 2014; Chen, 
Mak \& Li, 2013). As a result, correlations were found to be statistically significant, indicating a nomological validity of the measurement model (Table 6).

The composite reliability of the three factors was used to assess the internal consistency of the items in each construct. As stated by Bagozzi and Kimmel (1995), a composite reliability of 0.6 or above is considered satisfactory. The composite reliability of the three factors ranged from 0.692 to 0.890 , which indicated the acceptable construct reliability of the model. The overall model fit was also investigated using various indices (see Table 7, which is a supplementary file available on the web based version of this paper). The chi-square $\left(\mathrm{X}^{2}\right)$ test assesses the closeness of fit between the model and the data. The significant $\mathrm{p}$ value of $\mathrm{X}^{2}$ indicates a favourable fit. Several other indices, including RMSEA, GFI, AGFI, CFI, NFI, and TLI, were calculated to generate a holistic view of the model fit. The RMSEA value is categorized as the badness-of-fit measure in which a high value indicates a poor fit. The cut-off RMSEA value of $<0.07$ was used for this study considering the large sample size (Bagozzi, Yi, \& Phillips, 1991; Hair et al., 2010). The RMSEA value satisfied the above cut-off value, which further supported the favourable fit of the model. GFI, AGFI, CFI, NFI, and TLI all measured the goodness-of-fit of the model. All of these five indices were equal to or above 0.917 , which passed the cut-off value of 0.9 (Hair et al., 2010).

The same procedures were followed in both the high- and low-density groups. As shown in Tables 5, 6, and 7, both groups showed an acceptable convergent validity. They also demonstrated an acceptable discriminant validity. The composite reliability of both groups was higher than the cut-off value of 0.6 , which supported the internal consistency for all of the constructs. The indices that measured the overall model fit for each group were assessed (though the RMSEAs for both high- and low density groups were at marginal levels), and both models 
were deemed to be statistically well-fitted. All in all, the construct validity and reliability of the overall, high-density, and low-density samples were established. Eventually, 14 items from three factors were retained to form the Social Sustainable Scale (SSS) in tourism.

\section{Discussion}

Sirakaya-Turk et al. (2008) have argued that understanding resident perspectives towards sustainable tourism could benefit both policy makers and tourism organizations. Several previous studies have addressed the importance of sustainability in tourism destinations. However, few have highlighted the importance of social sustainability, and even fewer have provided comprehensive information about the measurement of social sustainability. Drawing upon the literature, this study applied a 10-step measurement development procedure to develop an exhaustive social sustainability measurement instrument.

Three factors were generated from the tests, namely, Host-Guest Conflict, Social Tolerance, and Social Acceptance. Host-Guest Conflict acts as a major component of SSS in tourism. The 8 items in this construct represent local complaints, control and perceptions of tourism. These were mainly adopted from the literature, notably negative impacts (Allen et al., 1993; Lankford \& Howard, 1994; Latkova \& Vogt, 2012; Perdue et al., 1990), restriction (Perdue et al., 1990; Latkova \& Vogt, 2012) and social cost (Choi \& Sirakaya, 2005). As discussed in the literature review, social impacts exist in each stage of the cycle and are exacerbated during the consolidation and stagnation stages due to the exhaustion of carrying capacity (Aledo \& Mazon, 2004; Yang et al., 2014). The high volume of visitation and rapid development of tourism 
facilities may arouse discontent and conflicts among local residents and may adversely lead to destination decline (Diedrich \& Garci'a-Buades, 2009).

In the Hong Kong case, Host-Guest Conflicts emphasize the complaints by local residents about tourists, especially those emanating from mainland China (i.e., inappropriate behaviours such as shouting, spitting, and eating in forbidden public areas) and the perceived conflict of interest between local residents and mainland tourists. Mainland Chinese tourists are frequently accused of displaying improper behaviours in public areas, such as eating in trains and speaking loudly. Differences in culture and social norms may be the main reasons for such conflicts. Though Hong Kong is now part of China, it experienced 150 years of colonial history, and researchers have identified cultural differences between the SAR and the mainland (Ye, Zhang \& Yuen, 2013). A dissimilarity of cultural backgrounds can distort the meaning of behaviours (Triandis, 1977), may lead to communication problems (Pearce, 1977, 1982) loss of emotional well-being (Lynch, 1960), and to the inhibition of social interactions (Robinson \& Nemetz, 1988). The dramatic increase of mass visitation has also demanded that residents share their resources with tourists (e.g., transportation and medical facilities). It has also resulted in a shortage of goods and price inflation for consumer goods, such as milk powder, daily necessities, and advanced technological devices (Chow, 2012). Overcrowding and a change in the appearance of their local environments have also increased the anxieties that are felt by Hong Kong residents.

Social Tolerance relates to resident wellbeing and the competence to get together with tourists. This is a newly explored factor in the present study which considers host feedback towards destination tourism capacity. In view of the possible influence of a large number of tourists, items under this dimension represent host evaluations of transportation facilities, medical facilities and social equity. Adopting such an approach may provide an efficient solution that 
appraises tourism capacity levels from a resident viewpoint. Medical tourism is for example, a service that has been promoted by the Hong Kong government and which developed rapidly between 2003 and 2012. In 2009 a total of 58,994 mothers gave birth in Hong Kong, of whom 29,766 (50\%) were from mainland China (“Mainland mothers,” 2010; Ye, Zhang, \& Yuen, 2011). Local Hong Kong mothers complained about the lack of vacant rooms in hospitals and about the high costs of hospitalization. These were attributed to the increased tourist demand for medical services (Policies, 2012). This phenomenon unfavourably affected the right of residents to use local facilities, thereby triggering hostile attitudes towards tourists.

Social Acceptance represents the extent to which local residents accept and appreciate tourists and tourism development. Building on previous reporting about visitor satisfaction (Choi \& Sirakaya, 2005), welcoming nature (Woosnam, 2012) and positive impacts (Allen et al., 1993; Lankford \& Howard, 1994; Latkova \& Vogt, 2012; Perdue et al., 1990) in the measurement of sustainability, this factor mainly assesses perceptions toward tourists and their positive impacts. It is of interest that, rather than preserving (Latkova \& Vogt, 2012) and sharing (Boley \& McGehee, 2014) the local culture, this factor identifies host appreciation that tourists help to bring an understanding of cultural diversity. Such differences reveal a unique appreciation of tourism, with the potential to improve host cultural competences (Ye et al., 2013). Being concerned about tourist satisfaction and appreciating the benefits brought by tourists are indicators of acceptance within the host society. To create socially sustainable tourism, it is essential that residents exhibit positive attitudes towards tourists. This will require interventions such as awareness campaigns within the community and in schools.

The contributions of the current research to knowledge are twofold. Theoretically, the Scale of Social Sustainability (SSS) in tourism acts as a pioneering and comprehensive 
instrument that provides a stringent measurement of social sustainability. It has been shown that three factors provide a multi-dimensional monitoring of the socially sustainable level of tourism, namely Host-Guest Conflict, Social Tolerance, and Social Acceptance. The measurement scale bridges the existing research gap and offers the prospect of future relational investigations between social sustainability and other constructs. Furthermore, compared with the existing sustainable tourism literature, this research is the first attempt to split the overall sample into two sub-samples by using a destination resident-attraction density. It further confirms the structural stability of the measurement and supports the generalization of the SSS to other contexts with various resident-attraction densities. Practically, the three indicators obtained from this study may help tourism planners and policy makers to evaluate current tourism development and to develop appropriate strategies that will support the balanced development of tourism. Tourism planners and policy makers worldwide generally emphasize the positive economic effects of tourism development. However, resident voices have been largely overwhelmed until their conflicts with and complaints against tourists reach critical levels. Long-term destination sustainability depends on an acceptance by residents of territorial plans for tourism development, improvements in community wellbeing, and harmony between hosts and guests. Social sustainability, with its direct influence on residents, is crucial to the success and sustainability of tourism. Therefore, tourism planners and policy makers should monitor social sustainability regularly with a view to obtaining a holistic opinion of the tourism market and its effects on society. This is preferable to relying exclusively on simplistic objective data, such as GDP indices and employment ratios. Social sustainability issues should also be considered and addressed in forthcoming tourism policies and strategies with a view to ensuring balanced and healthy tourism development. 


\section{Conclusion and Limitations}

Attaining a socially sustainable level of development has become more challenging because of the rapid expansion of tourism, particularly in Asia. Although tourism brings substantial economic benefits to host areas, it may also affect resident social and cultural values. This paradox should be addressed before the situation worsens, notably in the case of a city that is confronting tens of millions of annual tourist arrivals, including a million Chinese arrivals each week. A precise measurement instrument for evaluating social sustainability is urgently needed. However, no studies have yet examined the issue of ensuring social sustainability in a rapidly growing market.

Benefiting from the large sample size (1,839 responses), the CATI system with simple random sampling (within the quota that is set for each district), and the splitting of data into high and low density groups, the current research provides substantial evidence for the validity, reliability, and structural stability of the measurement instrument. This study contributes to the sustainable tourism literature generally and to the sustainable development of the Hong Kong tourism industry in particular. The measurement instrument that is developed in this study is a pioneering tool for assessing social sustainability from the perspectives of local residents and unveils future research possibilities on the relationships between tourism social sustainability and other attributes, such as economic sustainability. This instrument is also the first model that has been theoretically developed and empirically tested to evaluate the social sustainability of tourism in Hong Kong. Considering the mature levels of receiving mainland Chinese tourists, the scale generated from Hong Kong can provide a reference point for those destinations, which are targeting mainland Chinese tourists as the main inbound market. Furthermore, as the measurement instruments were further tested in both the high and low density areas, the robust 
and stable method can definitely be replicated in other tourism destinations with various tourism densities.

This model can also guide the formulation of tourism policies that are targeted at the Hong Kong tourism industry. By referring to the findings of this study on the social sustainability level of tourism development in Hong Kong, policy makers from both the public and private sectors can enhance their capacity to make informed decisions about tourism planning, marketing, and investment. More importantly, such kinds of investigation of social sustainability in tourism can be carried out on a regular basis, such as an annual survey, to constantly monitor the level of social sustainability and the change of residents' attitudes toward the tourism development. With this scale, policy makers can get alerts before the situation worsens. From the host residents' viewpoints, the large scale of the survey can help local residents be well informed about tourism development and become involved in the policy formation process. Given the stability of factor structures for different samples (i.e., high and low resident-attraction groups), and the diversity of Hong Kong' tourism attractions (both densely populated urban areas as well as the periphery), the developed measurement instrument can be generalized to a broader scale for regions and countries that face similar social issues emanating from the rapid development of the tourism industry.

However, as is the case with most research, this investigation was not without its flaws. As some of the items were generated from in-depth interviews and panel discussions, the meaning of some items were found to be double-barrelled, such as Q20 and Q21, which engendered potential misleading outcomes. Future research is highly encouraged to overcome this issue. The findings of this Hong Kong-based study should also be extended to other cultural 
contexts, such as western countries, to generate a more comprehensive view of the dimensions of social sustainability across diverse cultures.

\section{References}

Aledo, A., \& Mazon, T. (2004). Impact of residential tourism and the destination life cycle theory. In F. D. Pineda, C. A. Brebbia \& M. Mugica Sustainable Tourism (pp. 25-36). Southampton, Boston: WIT Press.

Allen, L. R., Hafer, H. R., Long, P. T. \& Perdue, R. R. (1993). Rural residents' attitudes toward recreation and tourism development. Journal of Travel Research, 31 (4), 27-33.

Ap, J. (1992). Residents' perceptions on tourism impacts. Annals of Tourism Research, 19 (4), 665-690.

Bagozzi, R. P., \& Kimmel, S. K. (1995). A comparison of leading theories for the prediction of goal directed behaviours. British Journal of Social Psychology, 34 (4), 437-461.

Bagozzi, R. P., Yi, Y. \& Phillips, L. W. (1991). Assessing construct validity in organizational research. Administrative Science Quarterly, 36 (3), 421-458.

Boley, B. B., \& McGehee, N.G. (2014). Measuring empowerment: Developing and validating the Resident Empowerment through Tourism Scale (RETS). Tourism Management. 45, 8594.

Boley, B. B., Maruyama, N., \& Woosnam, K. (2015). Measuring empowerment in an Eastern context: Findings from Japan. Tourism Management, 50, 112-122.

Boley, B. B., McGehee, N. G., Perdue, R. R., \& Long, P. (2014). Empowerment and resident attitudes toward tourism: Strengthening the theoretical foundation through a Weberian lens. Annals of Tourism Research, 49, 33-50.

Brougham, J. E. \& Butler, R. W. (1981). A segmentation analysis of resident attitudes to the social impact of tourism. Annals of Tourism Research, 8 (4), 569-590. 
Butler, R. W. (1980). The concept of a tourist area cycle of evolution: Implications for management of resources. Canadian Geographer 24 (1), 5-12.

Butler, R. W. (1999). “Tourism: An evolutionary perspective.” In J. G. Nelson, R. Butler, and G. Wall. Tourism and sustainable development: Monitoring, planning, and managing, Department of Geography Publication Series 37. Waterloo, Ontario, Canada: University of Waterloo.

Byrne, B. M. (2010). Structural equation modeling with AMOS: Basic concepts, applications, and programming (2nd Ed.). New York: Taylor \& Francis Group.

Carr, E. C. \& Worth, A. (2001). The use of the telephone interview for research. Journal of Research in Nursing, 6 (1), 511-524.

Chen, J. S. \& Hsu, C. H. C. (2001). Developing and validating a riverboat gaming impact scale. Annals of Tourism Research, 28 (2), 459-476.

Chen, Y., Mak, B., \& Li, Z. (2013). Quality deterioration in package tours: The interplay of asymmetric information and reputation. Tourism Management, 38, 43-54.

Choi, H. C. \& Sirakaya, E. (2005). Measuring residents' attitude toward sustainable tourism: Development of sustainable tourism attitude scale. Journal of Travel Research, 43 (4), 380-394.

Chow, V. (2012, February 1). Anger at Mainland visitors escalates with “locust” ad. South China Morning Post, City 1.

Churchill, G. A. (1979). A paradigm for developing better measures of marketing constructs. Journal of Marketing Research, 16 (1), 64-73.

Clark-Carter, D. (1997). Doing quantitative psychological research: From design to report. Hove, UK: Psychology Press Ltd.

Diedrich, A., \& Garcia-Buades, E. (2009). Local perceptions of tourism as indicators of destination decline. Tourism Management, 30 (4), 512-521.

Echtner, C. M. \& Ritchie, B. J. (1993). The measurement of destination image: An empirical assessment. Journal of Travel Research, 31 (4), 3-13. 
Fowler, F. J. (1984). Survey Research Methods. Thousand Oaks, CA: SAGE Publications Inc.

Fredline, E. \& Faulkner, B. (2000). Host community reactions: A cluster analysis. Annals of Tourism Research, 27 (3), 763-784.

Gripp, S. I., Luloff, A. E., \& Yonkers, R. D. (1994). Reporting response rates for telephone surveys used in agricultural economics research. Agricultural and Resource Economics Review, 23 (2), 200-206.

Groves, R. (1989). Survey Errors and Survey Costs. John Wiley \& Sons.

Gursoy, D. \& Rutherford, D. G. (2004). Host attitudes toward tourism: An improved structural model. Annals of Tourism Research, 31 (3), 495-516.

Hair, J. F, Black, W. C., Babin, B.J. \& Anderson, R. E. (2010). Multivariate Data Analysis (7th Ed.), Upper Saddle River, New Jersey: Pearson Education, Inc.

Hong Kong Census \& Statistics Department (2012). 2011 Population Census. Retrieved 15 September 2105, from http://www.statistics.gov.hk/pub/B11200552011XXXXB0100.pdf

Hong Kong Census \& Statistics Department (2013). Population. Retrieved 01 May 2103, from http://censtatd.gov.hk/hkstat/sub/ss20_tc.jsp

Hong Kong Tourism Board (2015). A Statistical Review of Hong Kong Tourism 2014. Retrieved Sep 3, 2015 from http://securepartnernet.hktb.com/filemanager/intranet/dept_info/private_20/paper/StatReview/StatReview2014/Stat_Review_2014_0.pdf

Hung, K. \& Petrick, J. F. (2010). Developing a measurement scale for constraints to cruising. Annals of Tourism Research, 37 (1), 206-228.

Keeter, S., Miller, C., Kohut, A., Groves, R. M., \& Presser, S. (2000). Consequences of reducing nonresponse in a national telephone survey. Public opinion quarterly, 64 (2), 125-148.

King, B., Pizam, A. \& Milman, A. (1993). Social impacts of tourism: Host perceptions. Annals of Tourism Research, 20 (4), 650-665.

Lankford, S. V. \& Howard, D. R. (1994). Developing a tourism impact attitude scale. Annals of Tourism Research, 21 (1), 121-139. 
Latkova, P., \& Vogt, C. A. (2012). Residents' Attitudes toward Existing and Future Tourism Development in Rural Communities. Journal of Travel Research, 51(1), 50-67.

Lavrakas, P. J. (1987). Telephone survey methods. Sampling, selection and supervision. Thousand Oaks, California: Sage.

Lawson, J.R. (2001). Community issues and resident opinions of tourism. Annals of Tourism Research, 28 (2), 269-290.

Liu, A. \& McKercher, B. (2014). The impact of visa liberalization on tourist behaviors-The case of China outbound market visiting Hong Kong. Journal of Travel Research. DOI: $10.1177 / 0047287514564599$

Lynch, K. (1960). The image of the city. Cambridge, MA: M.I.T. Press.

Mainland mothers giving birth in Hong Kong do not regret. (2010, August 2). Wen Wei Po, p. A02.

Marcus, A. \& Crane, L. (1986). Telephone surveys in public health research. Medical Care, 24 (2), 97-112.

McIntyre, G. (1993). Sustainable tourism development: Guide for local planners. Madrid, Spain: World Tourism Organization.

Milman, A. \& Pizam, A. (1988). Social impacts of tourism on central Florida. Annals of Tourism Research, 15 (2), 191-204.

Netemeyer, R.G., Bearden, W.O., \& Sharma, S. (2003). Scaling procedures: Issues and applications. London: Sage.

Nunkoo, R. \& Ramkissoon, H. (2012). Power, trust, social exchange and community support. Annals of Tourism Research, 39 (2), 997-1023.

Nunkoo, R., Smith, S.L.J. \& Ramkissoon, H. (2013). Residents’ attitudes to tourism: a longitudinal study of 140 articles from 1984 to 2010, Journal of Sustainable Tourism, 21 (1), 5-25. 
Pearce, P. L. (1977). Mental souvenirs: a study of tourists and their city maps. Australian Journal of Psychology. 29 (3), 203-210.

Pearce, P. L. (1982). Tourists and their hosts: Some social and psychological effects of intercultural contact. In S. Bochner Cultures in contact: Studies in cross-cultural interaction (p. 199). New York: Pergamon Press Ltd.

Perdue, R. R., Long, P. T., \& Allen, L. (1990). Resident Support for Tourism Development. Annals of Tourism Research, 17 (4), 586-599.

Policies need to be carried out to control mainland mothers giving births in Hong Kong. (2012, January 20), Wen Wei Po, Retrieved August 28, 2014 from http://paper.wenweipo.com/2012/01/20/WW1201200002.htm

Robinson, G., \& Nemetz, L. (1988). Cross-cultural understanding. Harlow, UK: Prentice Hall.

Robson, C. (1993). Real World Research. Oxford: Blackwell.

Sirakaya-turk, E., Ekinci, Y. \& Kaya, A. G. (2008). An examination of the validity of SUS-TAS in cross-cultures. Journal of Travel Research, 46 (4), 414-421.

Song, Z. B., Xing, L. J., \& Chathoth, P. K. (2015). The effects of festival impacts on support intentions based on residents' ratings of festival performance and satisfaction: a new integrative approach. Journal of Sustainable Tourism, 23(2), 316-337.

Su, Q. \& Lin, B.Y. (2004). Classification of residents in the tourist attractions based on attitudes and behaviors: A case study in XIdi, Zhouzhaung and Jiuhua Mountain. Geographical Research, 23 (1), 104-114.

Teye, V., Sönmez, S. F. \& Sirakaya, E. (2002). Residents' attitudes toward tourism development. Annals of Tourism Research, 29 (3), 668-688.

The United Nations Environmental Programme (UNEP) \& The United Nations World Tourism Organization (UNWTO) (2005). Making tourism more sustainable: A guide for policy makers. Madrid: UNWTO. 
The United Nations World Tourism Organization (UNWTO). (1995). Agenda 21 for the travel and tourism industry. Madrid: UNWTO.

The United Nations World Tourism Organization (UNWTO). (2004). Indicators of sustainable development for tourism destinations. Madrid: UNWTO.

To, T.W. (2006). Formation of tourism cluster as strategy for sustainable tourism development in Hong Kong: The case of Lantau. Proceedings of the Fourth China Tourism Forum, 197209.

Tosun, C. (2002). Host perceptions of impacts: A comparative tourism study. Annals of Tourism Research, 29 (1), 231-253.

Triandis, H. C. (1977). Subjective culture and interpersonal relations across cultures. Annals of New York Academy of Sciences, 285, Issues in Cross-Cultural Research, 418-434.

Ward, C. \& Berno, T. (2011). Beyond social exchange theory: Attitudes toward tourists. Annals of Tourism Research, 38 (4), 1556-1569.

Weaver, D. B. \& Lawton, L. J. (2001). Resident perceptions in the urban-rural fringe. Annals of Tourism Research, 28 (2), 439-458.

Williams, J. \& Lawson, R. (2001). Community issues and resident opinions of tourism. Annals of Tourism Research, 28 (2), 269-290.

Woosnam, K. M. (2012). Using Emotional Solidarity to Explain Residents' Attitudes about Tourism and Tourism Development. Journal of Travel Research, 51(3), 315-327.

World Commission on Environment and Development (WCED). (1987). Our Common Future, Oxford: Oxford University Press.

Yang J, Ryan C, \& Zhang L. (2014) Sustaining culture and seeking a Just Destination: governments, power and tension - a life-cycle approach to analysing tourism development in an ethnic-inhabited scenic area in Xinjiang, China. Journal of Sustainable Tourism, 22 (8), 1151-1174.

Ye, B. H., Zhang, H. Q. \& Yuen, P. P. (2011). Motivations and experiences of Mainland Chinese medical tourists in Hong Kong. Tourism Management, 32 (5), 1125-1127. 
Ye, B. H., Zhang, H. Q. \& Yuen, P. P. (2012). An empirical study of anticipated and perceived discrimination of Mainland Chinese tourists in Hong Kong: The role of intercultural competence. Journal of China Tourism Research, 8 (4), 417-430.

Ye, B. H., Zhang, H. Q. \& Yuen, P. P. (2013). Cultural conflicts or cultural cushion? Annals of Tourism Research, 43, 321-349.

Yu, C., Chancellor, H. C. \& Cole, S. T. (2011). Measuring residents' attitudes toward sustainable tourism: A reexamination of the sustainable tourism attitude scale. Journal of Travel Research, 50 (1), 57-63. 
Table 1. Procedure for Developing the Measurement Instrument

\begin{tabular}{|c|c|}
\hline Procedures & Techniques \\
\hline 1. Specify the domain of the construct & Literature search \\
\hline 2. Generate a sample of items & \begin{tabular}{|l} 
Literature search \\
In-depth interviews
\end{tabular} \\
\hline 3. Purify items and design a questionnaire & $\begin{array}{l}\text { Panel of experts, pilot study } \\
\text { (content validity) }\end{array}$ \\
\hline 4. Collect data & Survey \\
\hline 5. Explore dimensionality & Exploratory factor analysis \\
\hline 6. Assess reliability & Coefficient alpha \\
\hline 7. Assess factor structure stability (1) & $\begin{array}{l}\text { Data split: Conduct steps } 5 \text { and } 6 \\
\text { in both high and low resident- } \\
\text { tourism density groups }\end{array}$ \\
\hline 8. Assess reliability & Composite reliability \\
\hline 9. Assess validity & $\begin{array}{l}\text { Convergent validity } \\
\text { Discriminant validity } \\
\text { Nomological validity }\end{array}$ \\
\hline 10. Assess factor structure stability (2) & $\begin{array}{l}\text { Data split: Conduct steps } 8 \text { and } 9 \\
\text { in both high and low resident- } \\
\text { tourism density groups }\end{array}$ \\
\hline
\end{tabular}


Table 2. Results of the Telephone Reviews

\begin{tabular}{lr}
\hline Types & Number of calls \\
\hline Complete interviews & 1,839 \\
Partial interviews & 131 \\
Refused eligible units & 2,366 \\
No eligible units & 1,056 \\
Not contacted, but known eligible units & 7,401 \\
Other non-interviewed units & 40,207 \\
Total number of dialed telephone numbers & 53,000 \\
\hline
\end{tabular}


Table 3. Demographic Distribution of the Respondents $(n=1,839)$

\begin{tabular}{|c|c|c|}
\hline & Current Study (\%) & $\begin{array}{r}\text { Hong Kong Census } \\
\text { (Year 2011) }\end{array}$ \\
\hline \multicolumn{3}{|l|}{ Gender } \\
\hline Male & 44.5 & 46.7 \\
\hline Female & 55.5 & 53.3 \\
\hline \multicolumn{3}{|l|}{ Marital status } \\
\hline Single & 34.5 & 41.7 \\
\hline Married & 60.4 & 58.3 \\
\hline \multicolumn{3}{|l|}{ Age } \\
\hline 18-29 years & 17.5 & 17.0 \\
\hline 30-39 years & 11.7 & 19.2 \\
\hline 40-49 years & 17.7 & 21.0 \\
\hline 50-59 years & 23.9 & 19.8 \\
\hline 60-69 years & 14.4 & 11.0 \\
\hline 70 years or above & 14.0 & 12.0 \\
\hline \multicolumn{3}{|l|}{ Educational attainment } \\
\hline No schooling & 1.8 & 6.3 \\
\hline Primary & 10.0 & 16.5 \\
\hline Secondary/Matriculation & 44.5 & 50.0 \\
\hline Tertiary & 11.4 & 9.3 \\
\hline Bachelor or above & 31.9 & 18.0 \\
\hline \multicolumn{3}{|l|}{ Working status } \\
\hline Working & 56.6 & 59.7 \\
\hline Not working & 43.1 & 40.3 \\
\hline \multicolumn{3}{|l|}{ Industry occupation } \\
\hline Managers and administrators & 11.7 & 10.1 \\
\hline Professionals & 6.9 & 6.5 \\
\hline Associate professionals & 10.5 & 19.6 \\
\hline Clerks & 11.2 & 15.6 \\
\hline Service workers and shop sales workers & 6.5 & 16.2 \\
\hline Craft and related workers & 1.2 & 7.4 \\
\hline Plant and machine operators and assemblers & 2.1 & 5.0 \\
\hline Elementary occupations & 2.7 & 19.6 \\
\hline \multicolumn{3}{|l|}{ Job relation to tourism } \\
\hline Directly related & 4.4 & N/A \\
\hline Indirectly related & 8.9 & N/A \\
\hline Not related & 42.7 & N/A \\
\hline \multicolumn{3}{|l|}{ Monthly personal income (HKD) } \\
\hline 0 to 9,999 & 7.4 & 39.7 \\
\hline 10,000 to 14,999 & 10.3 & 21.4 \\
\hline 15,000 to 19,999 & 7.3 & 11.6 \\
\hline 20,000 to 29,999 & 10.4 & 12.1 \\
\hline
\end{tabular}


30,000 to 39,999

6.1

6.1

40,000 or above

9.6

9.1 
Table 4. Exploratory Factor Analysis Results for the Overall, High Density, and Low Density Samples

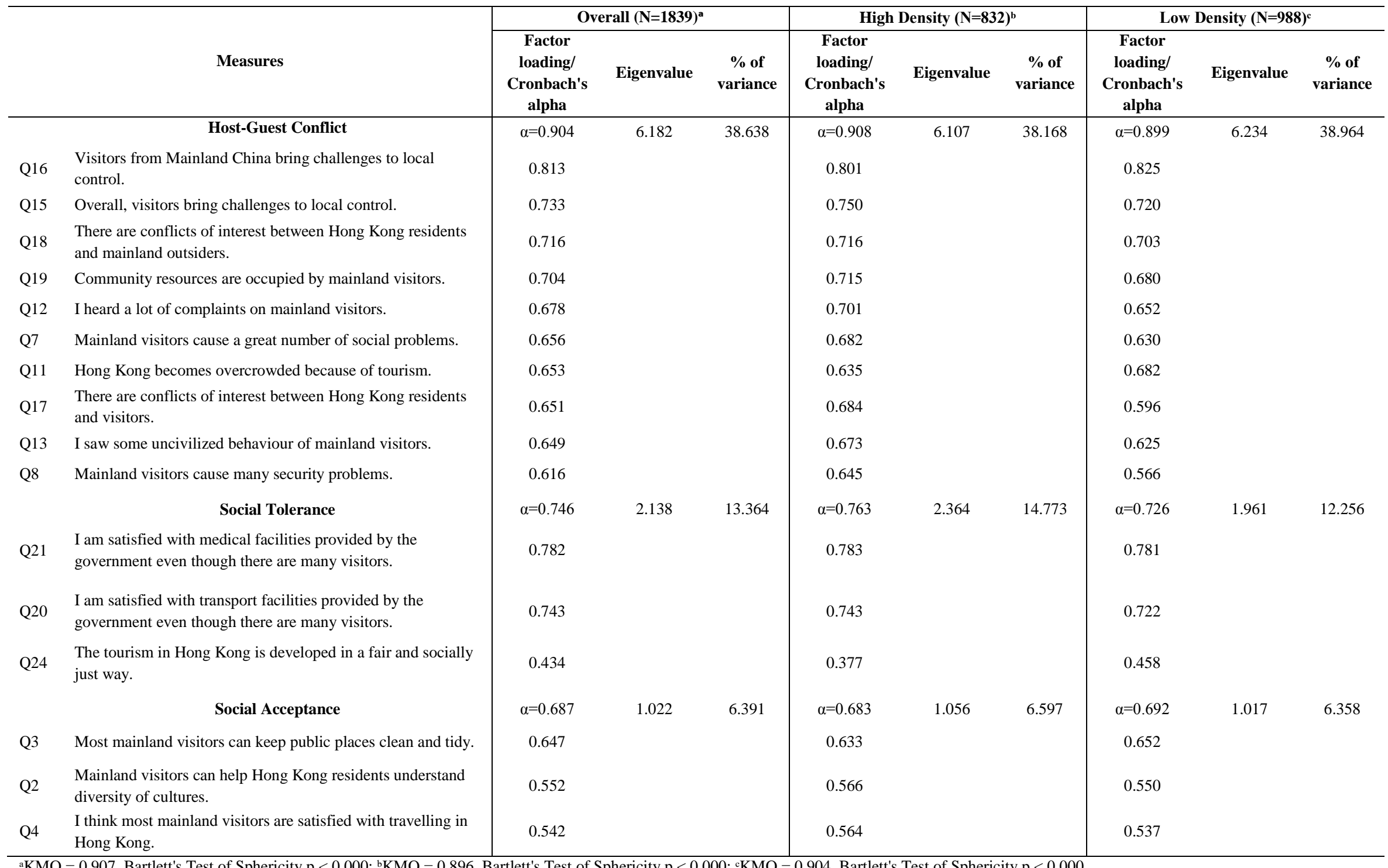


Table 5. Confirmatory Factor Analysis Results for the Overall, High Density, and Low Density Samples

\begin{tabular}{|c|c|c|c|c|c|c|c|c|c|c|}
\hline & \multirow[b]{2}{*}{ Measures } & \multicolumn{3}{|c|}{ Overall } & \multicolumn{3}{|c|}{ High } & \multicolumn{3}{|c|}{ Low } \\
\hline & & $\begin{array}{l}\text { Composite } \\
\text { Reliability }\end{array}$ & $\begin{array}{l}\text { Standardized } \\
\text { Factor Loading }\end{array}$ & $\mathbf{p}$ & $\begin{array}{l}\text { Composite } \\
\text { Reliability }\end{array}$ & $\begin{array}{l}\text { Standardized } \\
\text { Factor Loading }\end{array}$ & $\mathbf{p}$ & $\begin{array}{l}\text { Composite } \\
\text { Reliability }\end{array}$ & $\begin{array}{l}\text { Standardized } \\
\text { Factor Loading }\end{array}$ & $\mathbf{p}$ \\
\hline & Host-Guest Conflict & 0.890 & & & 0.892 & & & 0.887 & & \\
\hline Q16 & Visitors from Mainland China bring challenges to local control. & & 0.739 & $* * *$ & & 0.757 & $* * *$ & & 0.726 & $* * *$ \\
\hline Q18 & There are conflicts of interest between Hong Kong residents and mainland outsiders. & & 0.764 & *** & & 0.787 & $* * *$ & & 0.742 & *** \\
\hline Q19 & Community resources are occupied by mainland visitors. & & 0.741 & $* * *$ & & 0.747 & $* * *$ & & 0.732 & $* * *$ \\
\hline Q12 & I heard a lot of complaints on mainland visitors. & & 0.732 & $* * *$ & & 0.728 & $* * *$ & & 0.734 & $* * *$ \\
\hline Q7 & Mainland visitors cause a great number of social problems. & & 0.707 & $* * *$ & & 0.723 & $* * *$ & & 0.712 & $* * *$ \\
\hline Q11 & Hong Kong becomes overcrowded because of tourism. & & 0.656 & $* * *$ & & 0.629 & $* * *$ & & 0.677 & *** \\
\hline Q17 & There are conflicts of interest between Hong Kong residents and visitors. & & 0.625 & $* * *$ & & 0.657 & $* * *$ & & 0.590 & *** \\
\hline Q13 & I saw some uncivilized behaviour of mainland visitors. & & 0.700 & $* * *$ & & 0.689 & $* * *$ & & 0.706 & $* * *$ \\
\hline & Social Tolerance & 0.753 & & & 0.772 & & & 0.734 & & \\
\hline Q21 & $\begin{array}{l}\text { I am satisfied with medical facilities provided by the government even though there are } \\
\text { many visitors. }\end{array}$ & & 0.745 & $* * *$ & & 0.812 & $* * *$ & & 0.721 & $* * *$ \\
\hline Q20 & $\begin{array}{l}\text { I am satisfied with transport facilities provided by the government even though there are } \\
\text { many visitors. }\end{array}$ & & 0.760 & $* * *$ & & 0.741 & $* * *$ & & 0.751 & $* * *$ \\
\hline Q24 & The tourism in Hong Kong is developed in a fair and socially just way. & & 0.621 & $* * *$ & & 0.626 & $* * *$ & & 0.599 & $* * *$ \\
\hline & Social Acceptance & 0.692 & & & 0.683 & & & 0.700 & & \\
\hline Q3 & Most mainland visitors can keep public places clean and tidy. & & 0.770 & $* * *$ & & 0.761 & $* * *$ & & 0.777 & $* * *$ \\
\hline Q2 & Mainland visitors can help Hong Kong residents understand diversity of cultures. & & 0.605 & $* * *$ & & 0.596 & $* * *$ & & 0.621 & $* * *$ \\
\hline Q4 & I think most mainland visitors are satisfied with travelling in Hong Kong. & & 0.582 & $* * *$ & & 0.576 & $* * *$ & & 0.578 & $* * *$ \\
\hline
\end{tabular}


Table 6. Correlations of the Final Measurement Scale from Confirmatory Factor Analysis

\begin{tabular}{|c|c|c|c|}
\hline \multirow[t]{2}{*}{ Overall } & \multicolumn{3}{|c|}{ Correlations } \\
\hline & Host-Guest Conflict & Social Tolerance & Social Acceptance \\
\hline Host-Guest Conflict & 1.000 & & \\
\hline Social Tolerance & $-0.284(0.080)$ & 1.000 & \\
\hline Social Acceptance & $-0.396(0.157)$ & $0.498(0.248)$ & 1.000 \\
\hline$\overline{A V E}$ & 0.503 & 0.506 & 0.433 \\
\hline \multirow[t]{2}{*}{ High } & \multicolumn{3}{|c|}{ Correlations } \\
\hline & Host-Guest Conflict & Social Tolerance & Social Acceptance \\
\hline Host-Guest Conflict & 1.000 & & \\
\hline Social Tolerance & $-0.237(0.056)$ & 1.000 & \\
\hline Social Acceptance & $-0.232(0.054)$ & $0.351(0.123)$ & 1.000 \\
\hline AVE & 0.509 & 0.533 & 0.422 \\
\hline \multirow[t]{2}{*}{ Low } & \multicolumn{3}{|c|}{ Correlations } \\
\hline & Host-Guest Conflict & Social Tolerance & Social Acceptance \\
\hline Host-Guest Conflict & 1.000 & & \\
\hline Social Tolerance & $-0.255(0.065)$ & 1.000 & \\
\hline Social Acceptance & $-0.388(0.151)$ & $0.337(0.114)$ & 1.000 \\
\hline AVE & 0.501 & 0.481 & 0.441 \\
\hline
\end{tabular}

Note: All correlations are significant at $\mathrm{p}=0.01$. 
Table 7. Goodness-of-Fit Indices of Confirmatory Factor Analysis (17 items; Listwise deletion method)

\begin{tabular}{lrrr}
\hline & Overall & High & Low \\
\hline $\mathbf{X}^{2}$ & 570.279 & 314.727 & 366.776 \\
df & 74 & 74 & 74 \\
p value for $\mathbf{X}^{2}$ & 0.000 & 0.000 & 0.000 \\
RMSEA & 0.690 & 0.073 & 0.071 \\
GFI & 0.941 & 0.927 & 0.936 \\
AGFI & 0.917 & 0.897 & 0.909 \\
CFI & 0.935 & 0.929 & 0.931 \\
NFI & 0.926 & 0.910 & 0.915 \\
TLI & 0.920 & 0.913 & 0.915
\end{tabular}

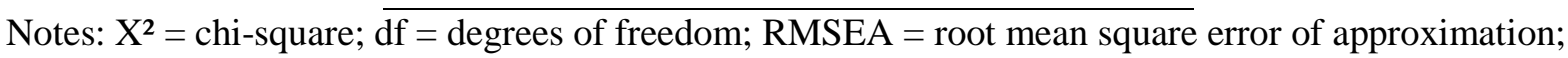
GFI = goodness-of-fit index; AGFI = adjusted goodness-of-fit index; CFI = comparative fit index; NFI = normed fit index; TLI $=$ Tucker Lewis index 